Fecha de recepción: abril 2020

Fecha de aceptación: mayo 2020

Versión final: junio 2020

\section{Museu Expandido e Estendido: Novos Designs de Apreciação}

Regiane Caminni Pereira da Silva ${ }^{(1)}$ e

Luciana Allegretti ${ }^{(2)}$

Resumo: Este artigo propõe a refletir sobre a apreciação de arte, nos dias de hoje, frente à comunicação tecnológica. A cultura, como um organismo vivo, em seus movimentos, gera e produz linguagens. Os lugares em que as cenas de recepção se processam são diversos: da visitação in loco à virtual. $O$ sentido da palavra lugar se potencializou com o universo on-line, processando novas formas de receber e sentir arte. $\mathrm{O}$ formato museu é o eixo para os questionamentos e o projeto Google Art Project - GAP é o corpus referencial que direciona o pensar da problemática. Ele abre possibilidades para vários sentires e escolhas do usuário, na relação com os objetos de arte, em uma mediação virtual. Nomeamos de design de apreciação, os novos formatos estéticos, para receber e interagir com arte, por sua funcionalidade para com o apreciador. A reflexão é fundamentada e articulada por meio das ideias sobre cultura, arte e museus, de Iuri Lotman, Milton J. Bennett, Néstor Canclini, Walter Zanini, Selma Thomas, respectivamente, entre outros.

Palavras chave: Tecnologia - Arte - Museu - Google Art Project - Virtual - Designs de Apreciação - Cultura - Mediação - Interatividade - Usuário.

[Resumos em espanhol e inglês nas páginas 37-38]

${ }^{(1)}$ Regiane Caminni Pereira da Silva: Artista visual e cênica. Mestre e Doutora em Comunicação e Semiótica pela PUC-SP. Professora da Faculdade de Tecnologia de São Paulo - FATEC - Centro Paula Souza - São Paulo.rcaminni@gmail.com

(2) Luciana Allegretti: Designer, professora do Centro Universitário FMU FIAM FAAM São Paulo. Mestre em Estética e História da Arte da Universidade de São Paulo. trampos. luciana@gmail.com 


\section{Contextualização: Museu, Arte, Apreciação}

Os modos de apreciar a arte estenderam-se para além de os núcleos elitizados com os avanços tecnológicos. Os recursos proporcionados pelas telecomunicações, gestões culturais, internet e digitalização possibilitaram novas formas de interação com as obras de arte e demais expressões artísticas. O acesso foi facilitado e mais pessoas manifestaram e manifestam o seu jeito de sentir, interagir e gostar de arte. Estamos tratando dos movimentos e avanços da cultura favorecidos por gerenciamentos tecnológicos. O gostar de arte popularizou-se ao atravessar fronteiras que limitava a sua apreciação a uma elite aristocratizada. A arte romantizada pela burguesia, advinda do poder de consumo e de um consequente ganho de status, gerados por meio da Revolução Industrial, diluiu-se diante do fácil acesso, do instantâneo e do poder de posse da imagem. Tem-se por instantes e isso parece bastar. Outro ganho é a possibilidade de organizar bancos de imagens em uma própria curadoria. Assim, vivemos uma era da facilidade ao acesso. Estamos recebendo oportunidades de nos desprender da obsessão de possuir e entrando na liberdade de escolha, possibilitada pelo fácil acesso. Uma era de democratização cultural. Desta forma, o saber-escolher se faz, cada vez mais, necessário às apreciações. Ter repertório, associado à sensibilidade perceptiva, é condição essencial para a apreciação. Um repertório que se caracteriza como conhecimento e não mero depósito de informações. O conhecimento é gerado pelo bem viver, ao fazer das informações aprendizados para novas experiências do bem sentir.

Assim, o conceito de museu, em nossos dias, transformou-se. Mesmo aquele museu, reconhecido como lugar físico que concentra arte e história, pede, pelos novos comportamentos da humanidade, em sua relação com a tecnologia, expansão e extensão. Hoje, ele se tece em rede e comunica-se por meio dela. A interação com estas instituições oferece contato antes e depois da visitação física, o que estende para outros modos de apreciar as expressões artísticas e dar preparação ou continuidade a elas. O museu físico está lá, mas outras formas de apreciação desenham-se em função de maneiras diversas, possibilitadas pela tecnologia. Alguns museus atuam tanto em formatos físicos como virtuais. Ou seja, oferecem diferentes possibilidades de interação para apreciar a obra, abrindo espaço para que o visitante internauta crie a sua própria curadoria por meio de gostos peculiares. Este é o museu expandido.

Os movimentos que expandem e estendem a comunicação artística não são sustentados exclusivamente por uma rede tecnológica. Ela é a facilitadora. Mas, são expandidos principalmente pelos modos de vida da cultura contemporânea, em movimentos transmidiáticos de expansão. O prefixo trans, dicionarizado como movimento para além de, através de, posição para além de, mostra-nos que a comunicação se tece, conforme vai passando entre e por mídias diversas. Passar por, estabelecer e estender relações, ir para outro lugar ou ambiente, permitem possibilidades infinitas de produções. Os movimentos culturais, nesta rede de comunicações, criam relações que geram conhecimentos, dando acesso ao gosto de apreciar.

Esta observação pode parecer bizarra. Porém é fato que mídias e tecnologia fomentam os acessos à arte. O que chamamos a atenção é que estes recursos tornaram e fazem parte das práticas de vida contemporânea. Portanto compõem as ações culturais que estamos vivendo. É a cultura abordada e vivida em rede. Deleuze retratou como rizoma, Edgar 


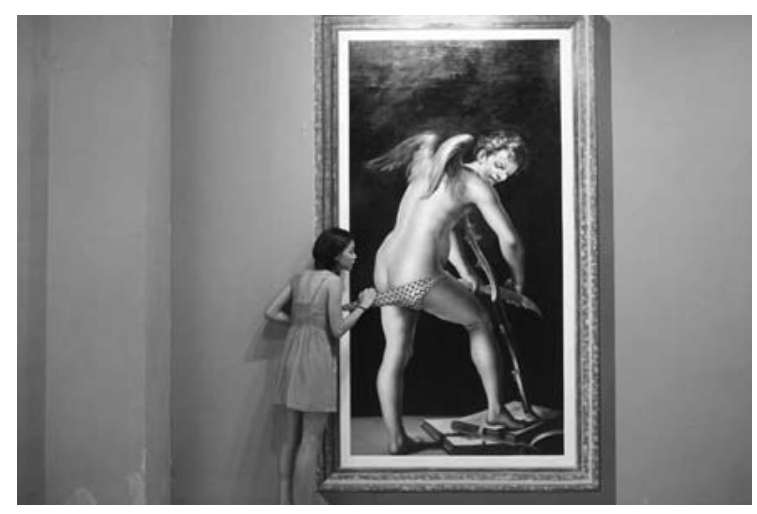

Figura 1. Museu Interativo Art on Island.

Morin como pensamento complexo e Iuri Lotman como semiosfera. E é, nesse contexto, que propomos a reflexão sobre o que é apreciação em arte, hoje, diante da tecnologia que temos. O formato museu é o eixo para os nossos questionamentos e o projeto Google Art Project - GAP é o corpus referencial que direciona o pensar desta problemática, abrindo possibilidades para vários sentires.

Pode-se questionar qual a realidade para a apreciação diante do leque de formatos para museus. Inteirar-se da política de museus, na relação com a tecnologia, é permitir-se a novos modos de apreciação. Esta situação muda a forma de apreciar, certamente. Novos designs de apreciação surgem com novas formas de receber arte física ou virtualmente. E outro ponto para pensarmos é como o corpo recebe e interage em diferentes ambientações, sejam físicas ou virtuais. Não deixando de esquecer que o corpo que recebe está sempre na sua condição física. Para isso, é importante conhecermos a historicidade dos museus. O museu nasceu privado como uma coleção de objetos reunidos por determinados nobres e pessoas abastadas. Os acervos eram chamados de "Câmaras de maravilhas" durante o Renascimento e "Gabinete de curiosidades" a partir do século XVI. Eram salas repletas de objetos de naturezas diferentes, desde plantas exóticas e animais empalhados, até objetos de tecnologia, produzidos em materiais luxuosos como o astrolábio, e obras de arte. Posteriormente, o museu tornou-se público como uma ferramenta do estado moderno e com função pedagógica. O British Museum (1753) e Louvre (1793) são os dois pioneiros, nesse contexto.

O museu público, atualmente, recebe uma demanda enorme de visitantes, ávidos por observar, absorver e envolver-se com as obras expostas. Embora esteja presente a moda das selfies $^{1}$, que atrai polêmicas, proibições e o surgimento de instituições próprias para tanto ${ }^{2}$. A audiência sente necessidade, de alguma forma, de comprovar e divulgar sua presença em determinada exposição ou museu (Figura 1). 
Entretanto a própria arte mudou. Muitas vezes, não se trata mais de um objeto bi ou tridimensional exposto de forma estática entre quatro paredes. Hoje, a tecnologia faz parte do desenvolvimento e da produção artística. Processos iniciados pela fotografia, artes cinéticas e computador influenciaram em demasia o fazer arte. Os movimentos destas mídias foram indiscutivelmente transmidiáticos. Eles expandiram-se e atingiram o modo de processar arte.

Uma reviravolta de grandeza maior operou-se no cenário da arte tecnológica com a assimilação da informática pelos artistas de várias áreas. [...] os computadores digitais logo foram assimilados e pesquisados com uso próprio pelo pensamento da arte. As máquinas "cerebrais" tornaram-se instrumento de novas dimensões da criatividade e também passaram a influir nas formas de arte em vigor (Zanini, 2003, p. 11) ${ }^{3}$.

Se a arte mudou, o museu deve, teoricamente, mudar também. Os curadores Harald Szeemann e Walter Hopps desafiaram a burocracia das instituições ao questionarem o formato da produção de exposições. Foi aberto o precedente necessário às modificações que o museu contemporâneo precisava contemplar.

Atualmente, as exibições incluem corredores com monitores de TV, fotografias, salas com espelhos em ângulos incomuns etc. Obras que podem e, por vezes, devem ser tocadas. Obras de escala monumental, performances e outras características, até então inusitadas. As mostras contemporâneas não lidam apenas com a ideia de apresentação expandida de arte, mas também tangem parâmetros, conceitos virtuais e experimentações que envolvem participação ativa do público ao contemplar (Fowle, 2007, p. 33).

Diante do contexto tecnológico, o que acontece com as tradicionais obras de arte? Os quadros e esculturas que abarrotam o acervo do Louvre? Estariam abandonadas e substituídas pelos novos conceitos artísticos? Não. Pelo menos não é o que é percebido nas imensas filas presentes em museus tradicionais. Tampouco em exposições de artistas mundialmente famosos, apresentadas em diversos museus e casas de cultura. Curadores fazem tudo que podem para trazer uma seleção de obras consideradas significativas, na história da arte. Mas, afinal, por que as pessoas continuam indo aos museus? Selma Thomas (2000) faz uma observação considerável em seu texto Mediated realities: a media perspective. "A mídia (tecnologia por si só) não traz visitantes ao museu. [...] Por que eles [a audiência] vêm ao museu? A resposta tradicional é que vêm em busca de 'coisas' - artefatos reais, obras de arte reais, objetos reais" (p. 1).

Portanto, na contemporaneidade, em que a arte mudou várias vezes de suporte e expandiu suas fronteiras além de as quatro paredes do museu, o público ainda é ávido pelas obras ditas reais. Aquelas consideradas com aura. Objetos únicos produzidos por um artista e inseridos na história da arte tradicional.

Porém, muitas dessas grandes obras são proibidas de deixarem determinados museus. É preciso uma grande quantidade de dinheiro e tempo para que um admirador de arte possa viajar o mundo e vislumbrar os tesouros guardados e protegidos nestas grandes caixas institucionais. Para resolverem esse problema, divulgarem as instituições e adaptarem-se às novas tecnologias, os museus criaram seus próprios sites, na web, nos quais disponi- 
bilizam alguma informação, uma parte do acervo, textos educativos etc. Cada instituição decide o que disponibiliza. A entrada do museu na era digital já tinha sido antecipada por Zanini (1976):

Para consecução de suas tarefas culturais e educacionais, o museu tende a espraiar-se para longe das paredes de sua sede, estabelecendo liames de verdadeiros alcances comunitários, possíveis com a utilização dos recursos atuais da comunicação [...] Esta estratégia, que poderá obrigar os museus do futuro a ter seus próprios canais de transmissão, não significaria tão somente a divulgação ou uma genérica democratização do museu, mas a capacitação a formulações específicas da criatividade. A atividade do museu reunirá assim atividades centralizadoras e descentralizadoras, componentes e uma ampla pragmática conjugada(p. 23) $)^{4}$.

Todavia, muitos desses sites são limitados e com pouca informação de pesquisa. Na realidade de um mundo globalizado e informatizado abre-se espaço para um passo a mais dentro da ideia de um museu expandido e estendido. Um endereço virtual em que haja a possibilidade de visitação aos mais importantes museus do mundo, não apenas para ver pequenas imagens de obras, mas sim para obter a experiência de andar pelo museu. Apesar de parecer um conceito utópico, foi o que a multinacional Google produziu e lançou no dia primeiro de fevereiro de 2011: O Google Art Project. O GAP é uma plataforma digital de uso público criada em parceria com diversos museus do mundo por um pequeno grupo de funcionários da empresa. Os funcionários, incentivados pela "política dos 20\%", passaram a discutir o uso da tecnologia do Google para simplificar o acesso à arte e aos museus. Vinte por cento deles dedicam vinte por cento do tempo de trabalho para criação dos próprios projetos ${ }^{5}$.

Pelo conceito tecnossocial participativo, uma entidade cultural, como o museu, precisa atualizar-se. A própria ideia de atualização tecnológica, apesar de obviamente prática e facilitadora do cotidiano, sofreu resistência dentro das instituições. Entretanto, melhorar a catalogação e a consulta do acervo das instituições está longe de ser o ideal para participar do cenário sociocultural. Tampouco a simples criação de um website é suficiente para sanar as necessidades de um público participativo e colaborativo.

Por isso, é necessária uma reflexão sobre qual seria a solução para criar uma maior divulgação internacional, manter o consumidor interessado e levar cultura, como conhecimento, para o mundo. É importante que o acesso à arte eduque, informe e gere diálogos. Muitas vezes, o contato com obras é inacessível para a maioria das pessoas do planeta. $\mathrm{O}$ Google Art Project tornou-se um centro de convergência de museus do mundo inteiro, ao abrir a possibilidade de vivenciar a experiência museológica por meio de um computador. 


\section{Museu em Transformação}

As formas de fazer, receber e sentir arte estão sempre em transformação. O tempo, na cultura, é quem determina os modos de viver de um povo, caracterizando gostos, opiniões e expressões. O museu é um dos formatos mais conhecidos, historicamente, para a recepção em arte. Ao longo das épocas, ele ganhou diferentes ambientações físicas, mas sempre se preservou como um lugar que reúne um considerável número de objetos. Sejam estes de ordem documentária, artística ou expressiva. Com a tecnologia digital, o virtual ganhou status de lugar.

As primeiras tentativas de usar um computador no museu foram nos anos sessenta, entretanto ele era caro, imenso e difícil de usar. O primeiro equipamento para auxílio ao visitante foi de 1952. Era manual e explorava a ideia de mediar a experiência de cada usuário, individualmente. Tecnologias, baseadas no rádio ou em gravações, foram pesquisadas (Figura 2), mas foi só recente e efetivamente que áudios guias se desenvolveram. Em 1993, um guia digital da coleção permanente do Louvre foi lançado e, por consequência, a maioria dos grandes museus mundiais adotou a virtualidade até o final do século XX (Tollon, 2008, p. 13-14).

Nos anos setenta, na geração dos primeiros microcomputadores, mais baratos e um pouco mais fáceis de operar, a informação eletrônica entrou para os museus. Entretanto esses aparelhos ainda eram complexos e requeriam pessoas qualificadas para operá-los. Ainda não familiarizados com a tecnologia, muitos museus acabaram se desiludindo.

Na segunda fase da computadorizarão do museu, a tecnologia já estava mais amigável com o usuário. Os funcionários das instituições entravam com a informação no equipamento, utilizando teclados ao invés de usar os cartões perfurados da geração anterior (Figura 3). A partir daí, mais coleções puderam ser registradas digitalmente.

Apesar de o esforço, para criação e crescimento de projetos computadorizados, dentro dos museus, ainda faltavam programas específicos. O primeiro programa para o meio foi o pacote Detroit Arts Registration Information System ou DARIS de 1982. Ele era programado para a catalogação, pesquisa e controle de coleções. Junto com o DARIS, vinha outro pacote chamado DAMIS (Detroit Arts Managment Information System). Este incluía programas de contas, associação, levantamento de fundos, monitoramento da gift shop e lista de mailing. O sistema inteiro era disponível, gratuitamente, para organizações sem fins lucrativos, mas tinha manutenção anual paga.

Os anos oitenta assistiram uma grande proliferação de microcomputadores. Mais potentes e de tamanhos cada vez menores, ainda carregavam os mesmos problemas das duas gerações anteriores para os museus. O custo, a difícil manipulação para os profissionais da área dos museus e poucos programas voltados, especificamente, para os problemas museológicos dificultavam uma relação benéfica com a tecnologia.

Nos anos noventa, ela já foi mais acessível e portátil. A partir daqui um novo obstáculo surgiu: o medo de investir em equipamentos obsoletos em um curto período de tempo. Entretanto a década trouxe novas necessidades com a proliferação da tecnologia e a internet cada vez mais acessível. O museu não precisava mais desenvolver-se apenas internamente. Tornou-se necessário ir além de suas paredes e habitar na WEB (Williams, 2010, pp. 15-20). Foi necessário expandir e estender o museu físico, de modo que fosse acessado 


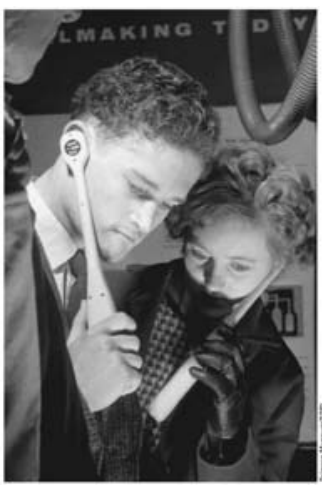

$2 a$.

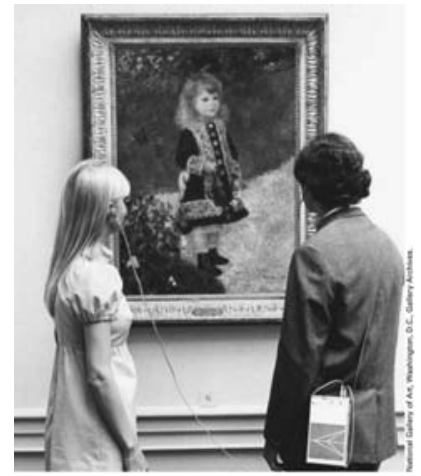

2c.

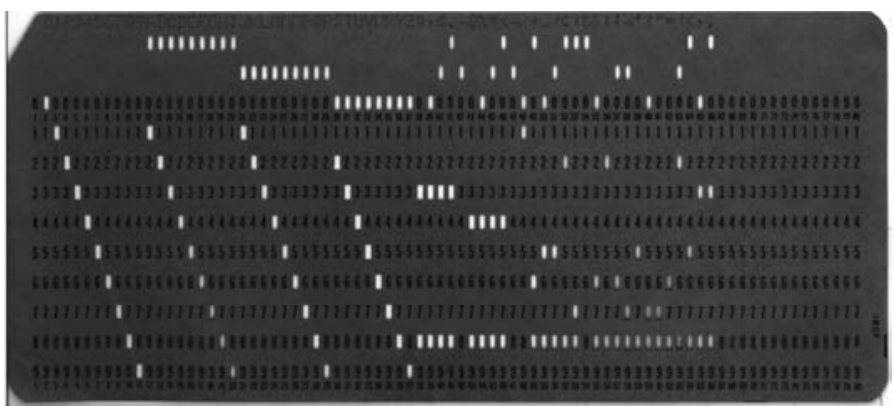

3.

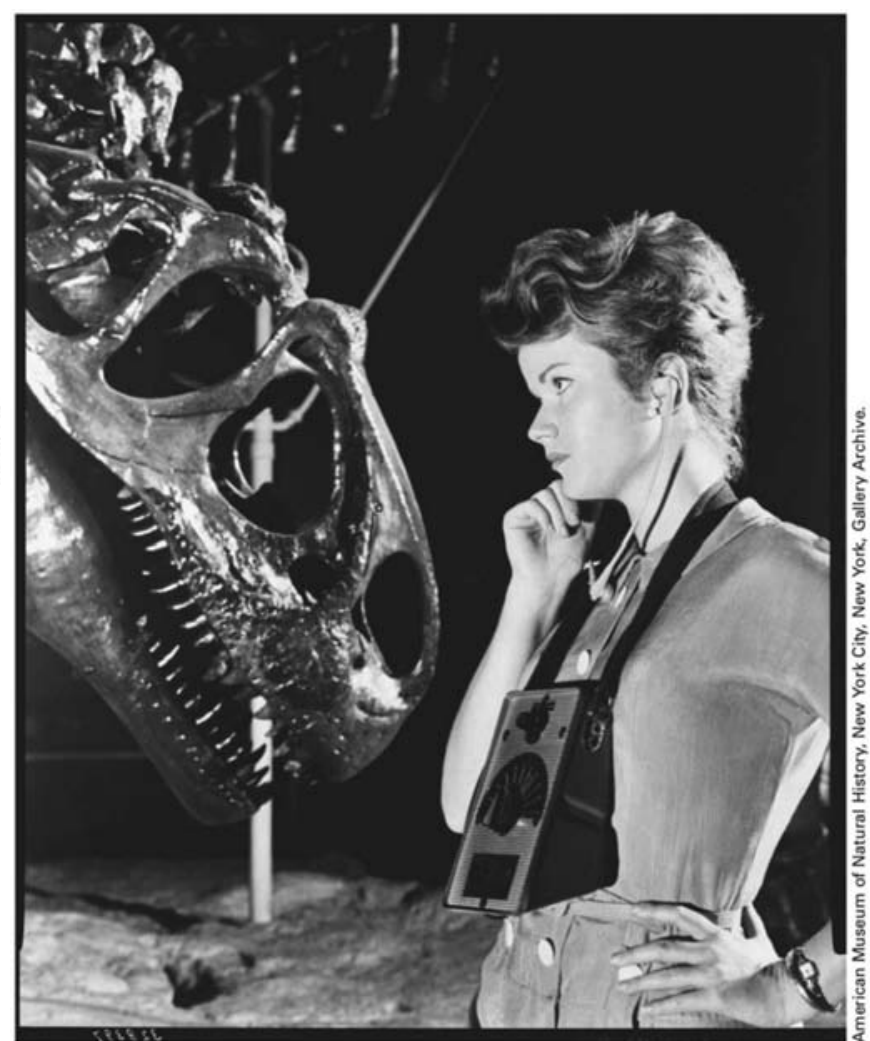

$2 b$.
Figura 2a, 2b y $2 c$.

Dispositivos de orientação guiada para museus nos anos 60. Figura 3. Cartão perfurado - precursor da memória usada em computadores. 
por outros formatos de comunicações e que permitisse a consulta e continuidade de suas informações.

Desde a popularização da internet, um dos campos mais promissores e discutidos foi a divulgação de informação e cultura pela rede. Inúmeras bibliotecas digitais disponibilizam seus conteúdos on-line. Enciclopédias "orgânicas", como a Wikipedia, são constantemente atualizadas e visitadas por estudantes e curiosos por todo o planeta. Até mesmo aulas são ministradas à distância. A inclusão das artes visuais, nesta tendência, era apenas uma questão de tempo.

Inicialmente, dadas às limitações de velocidade de transferências de dados e a baixa definição das câmeras digitais, era possível apenas registrar imagens pequenas e graficamente abreviadas. Funcionavam como resumos das obras que convidavam a visitar o original. Museus, galerias e vendedores de arte on-line, como a Amazon, publicavam tais imagens em baixa definição como uma pequena amostra do que seria ver ou adquirir a obra real. A partir de fevereiro de 2011, as exposições digitais de arte iriam tomar dimensões muito maiores. A multinacional de internet Google lançou, nesta data, o Google Art Project - um projeto de publicação de arte por meios digitais (Figura 4). A Google teve ferramentas para lançar uma ambiciosa iniciativa de divulgar arte gratuitamente para quem quisesse e em qualquer lugar do mundo. Isso foi possível pelas câmeras de altíssima definição, capazes de captar detalhes além de o olho humano, pelo seu famoso mecanismo de busca e recursos financeiros e humanos vultosos.

Inicialmente, o Google Art Project fez parcerias com dezessete museus e galerias pelo mundo. Escolheu entidades de peso, história e prestígio, como o Museu Van Gogh em Amsterdam, o MoMA e o MET em Nova Yorque, a galeria Uffizi em Florença e o Hermitage em São Petersburgo. Hoje o número de galerias, museus e exposições chega a quase seiscentos, incluindo Inhotim, Museu Afro Brasil, MAM e Pinacoteca do Estado de São Paulo, no Brasil (Figura 5).

Esta plataforma não é inédita, outras iniciativas já ocorreram por instituições como Amazon e Getty. Mas, segundo Amit Stood 6 , chefe e idealizador do projeto, "a diferença entre esse e outros websites é que todas as imagens estão em alta resolução, bem como enriquecido com uma série de ferramentas de meta-data". Além de as fotografias em definição altíssima e a abrangência mundial, o GAP introduziu três novos diferenciais em sua plataforma (Figura 6). A primeira é a intenção do projeto como recurso educacional ao invés de mero catálogo de arte. As diretrizes do projeto incentivam o uso da ferramenta para pesquisa acadêmica. Temos aí uns dos mecanismos que sustentam a ideia de museu estendido. A segunda é uma interface que possibilita o visitante a "caminhar" pelos corredores do museu, vendo em seu monitor, em primeira pessoa, todo o percurso de cada galeria ou exposição. Esta interface expande, culturalmente, o conceito de museu. Ela é baseada na tecnologia Google Street View, conhecida por mostrar as ruas das cidades como se o apreciador caminhasse por elas, com imagens recolhidas em intervalos e compostas como um caminho virtual on-line (Figura 7). 

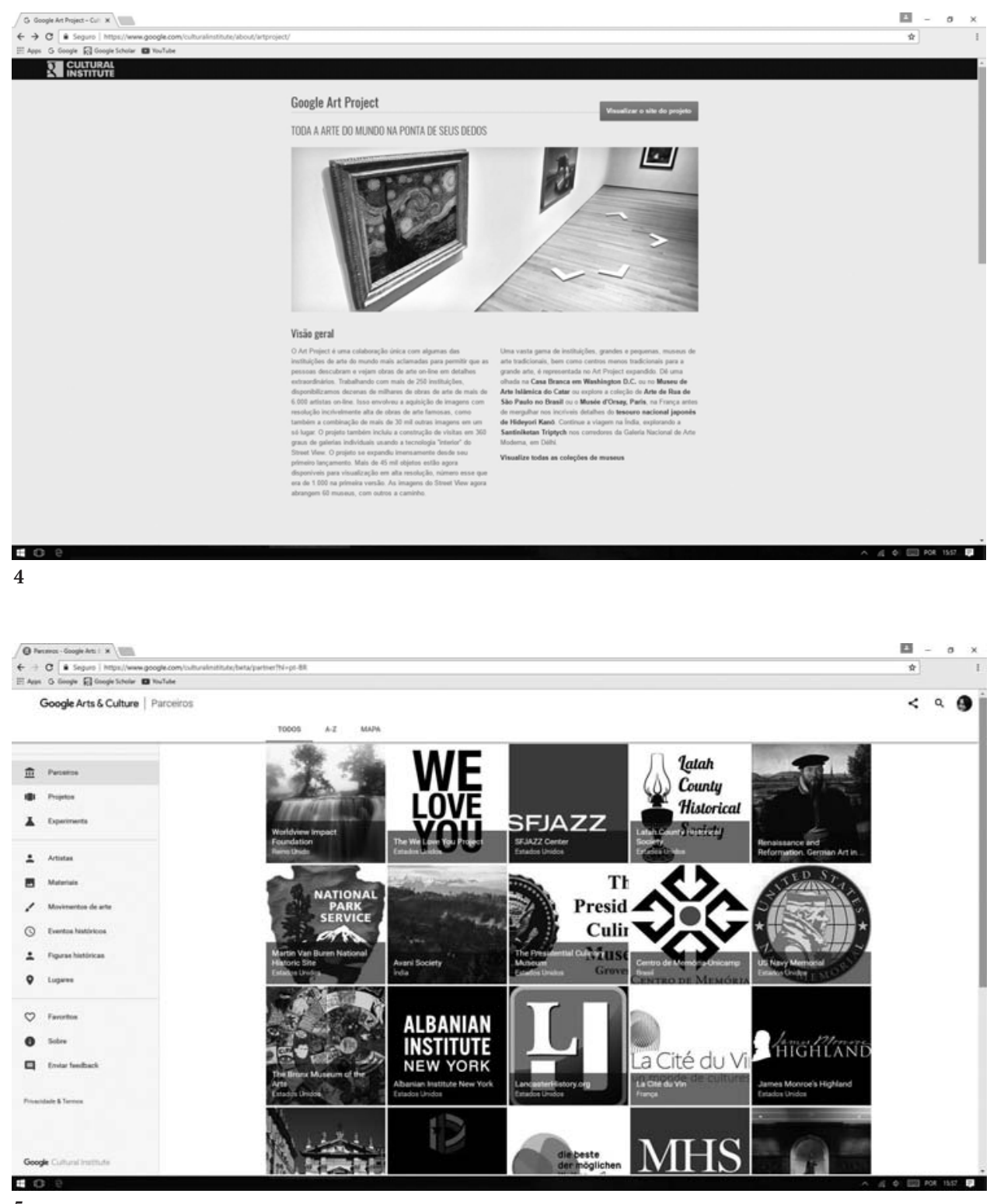

5

Figura 4. Home page do Google Art Project. Figura 5. Página com a lista de coleções dos museus e galerias parceiros do GAP. 


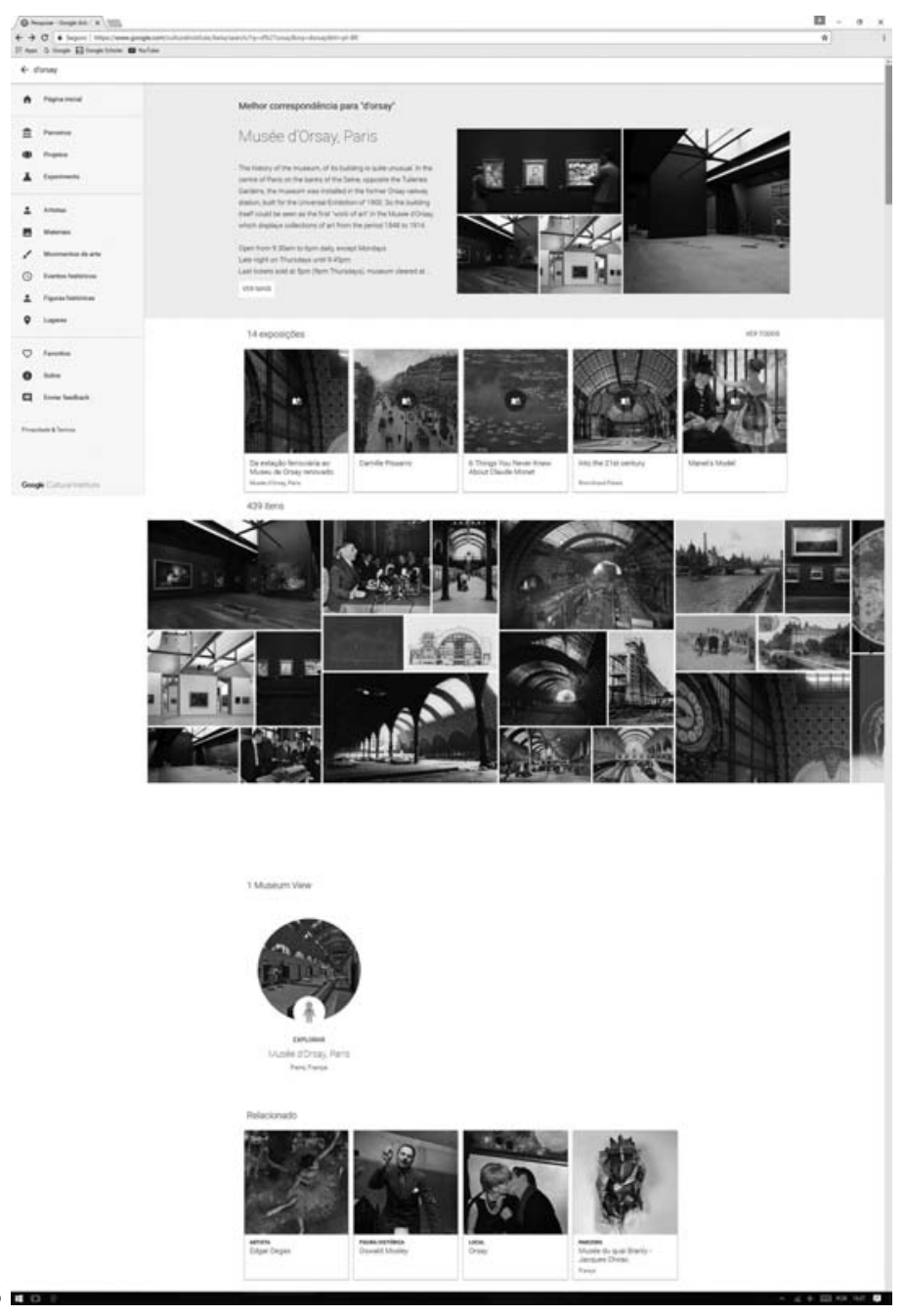

Figura 6. Musée d'Orsay, Paris, a página do museu com informações. Múltiplas opções de navegações.

Figura 7. Musée d'Orsay, Paris, museu view.

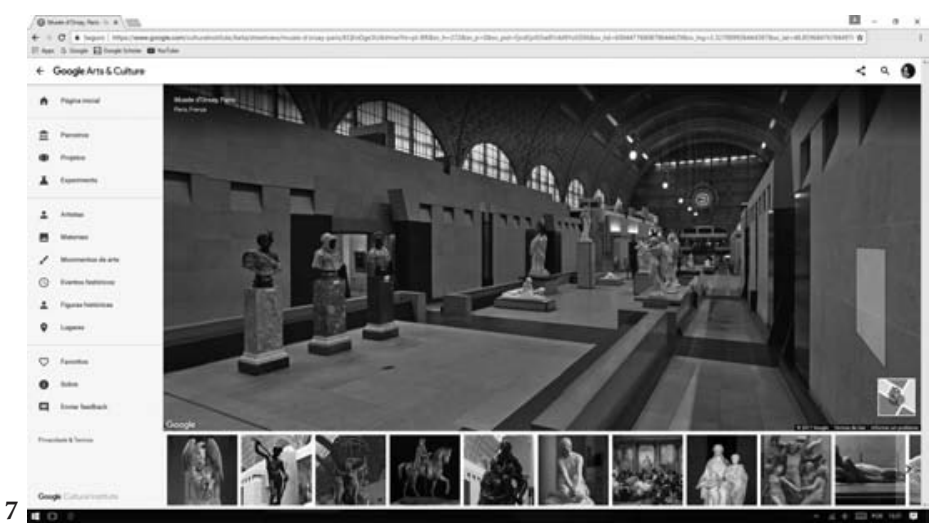


Há uma grande inserção de rede social (Figura 8) com as plataformas e aplicativos da Google. Com estes recursos os usuários podem ser curadores digitais. Podem criar suas próprias coleções e divulgá-las no próprio site do GAP. O aplicativo Google+ além de compartilhar conteúdos, com outras pessoas on-line, capacita discussões sobre arte e curadoria virtual entre seus participantes.

No início, somente uma obra de cada um dos dezessete museus iniciais foi escolhida para o tratamento em gigapixels. The Apparition of Christ to the People, de Alexander Andreyevich Ivanov, é uma delas. Podem-se observar com clareza as pessoas escondidas atrás da árvore (Figuras 9 e 10).

Atualmente, o catálogo de obras, em altíssima resolução, é mais amplo. É possível ver detalhes ínfimos e que, normalmente, passariam despercebidos em mosaicos, telas e objetos arqueológicos. Cada imagem supera a marca de sete bilhões de pixels. Para se ter uma ideia comparativa, as câmeras comerciais mais sofisticadas, no momento, possuem sensores de trinta e cinco megapixels ou trinta e cinco mil pixels.Com o advento do GAP em 2011, a Google criou uma central para controlar e desenvolver todos seus projetos culturais. O Google Cultural Institute (Figura 11), localizado em Paris, conta com projetos diversos, como o Google World Wonders que possibilita visitação on-line de locais de patrimônio mundial. E o Google Historic Moments que analisa e expõe fotografias históricas de importantes eventos da humanidade. Todos os recursos do Google Cultural Institute são interligados pela rede social Google+, possibilitando discussões globais, galerias personalizadas de imagens e pesquisa e divulgação acadêmicas.

O usuário do GAP é estimulado a entrar em diversos serviços da marca. Para acessar a plataforma, ele deve fazer uma conta no provedor de e-mails Gmail (Google Mail). Recebe recomendações para utilizar o navegador Google Chrome. As vídeo aulas e palestras serão assistidas no YouTube (que pertence ao Google). Todas essas informações podem ser compartilhadas pelo Blogger, Google Drive, Google+ e Google Hangouts. Cada plataforma utilizada garante mais informação sobre as atividades do usuário e um perfil de comportamento dos mesmos pode ser sintetizado para análise da corporação. 

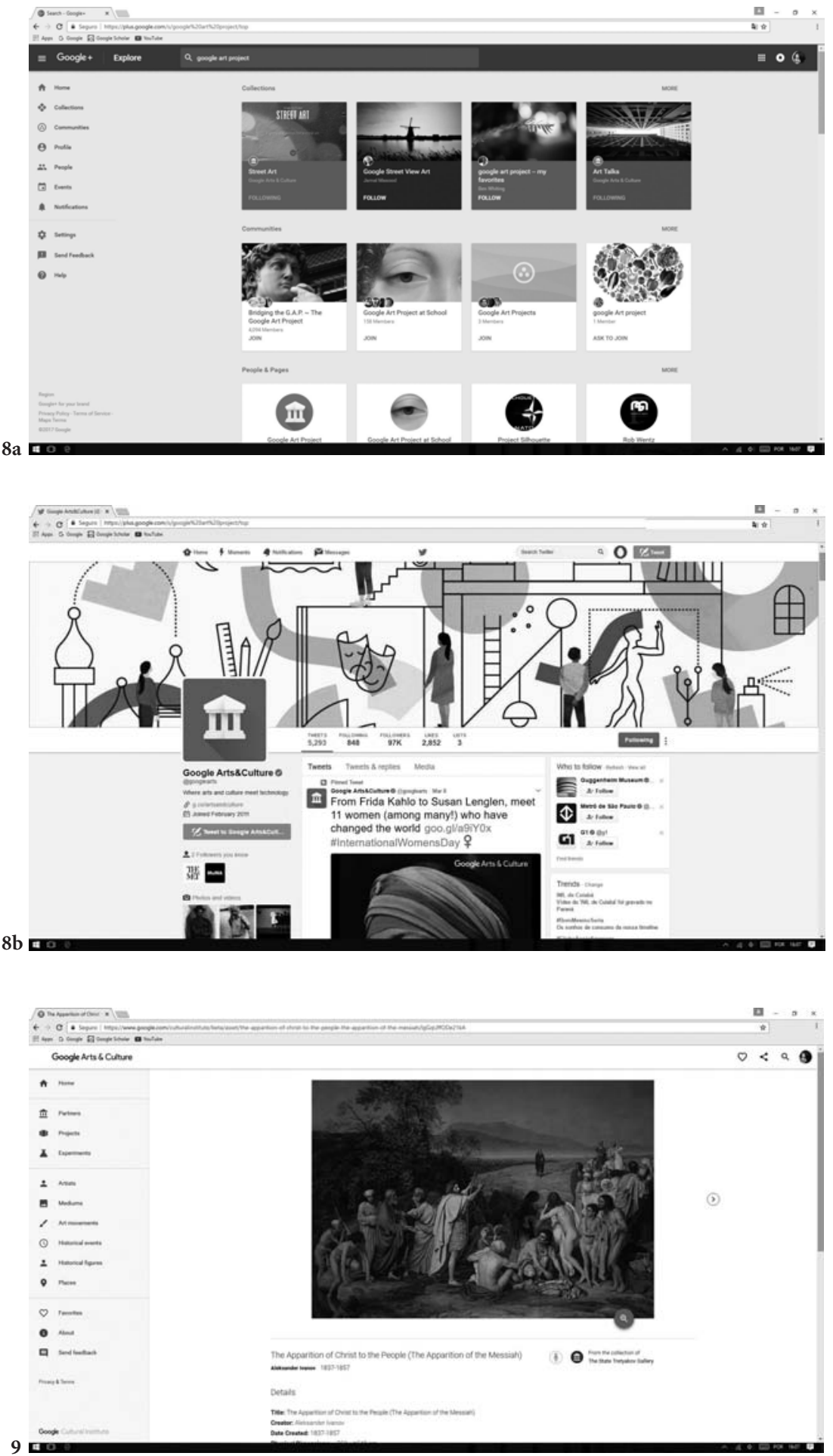

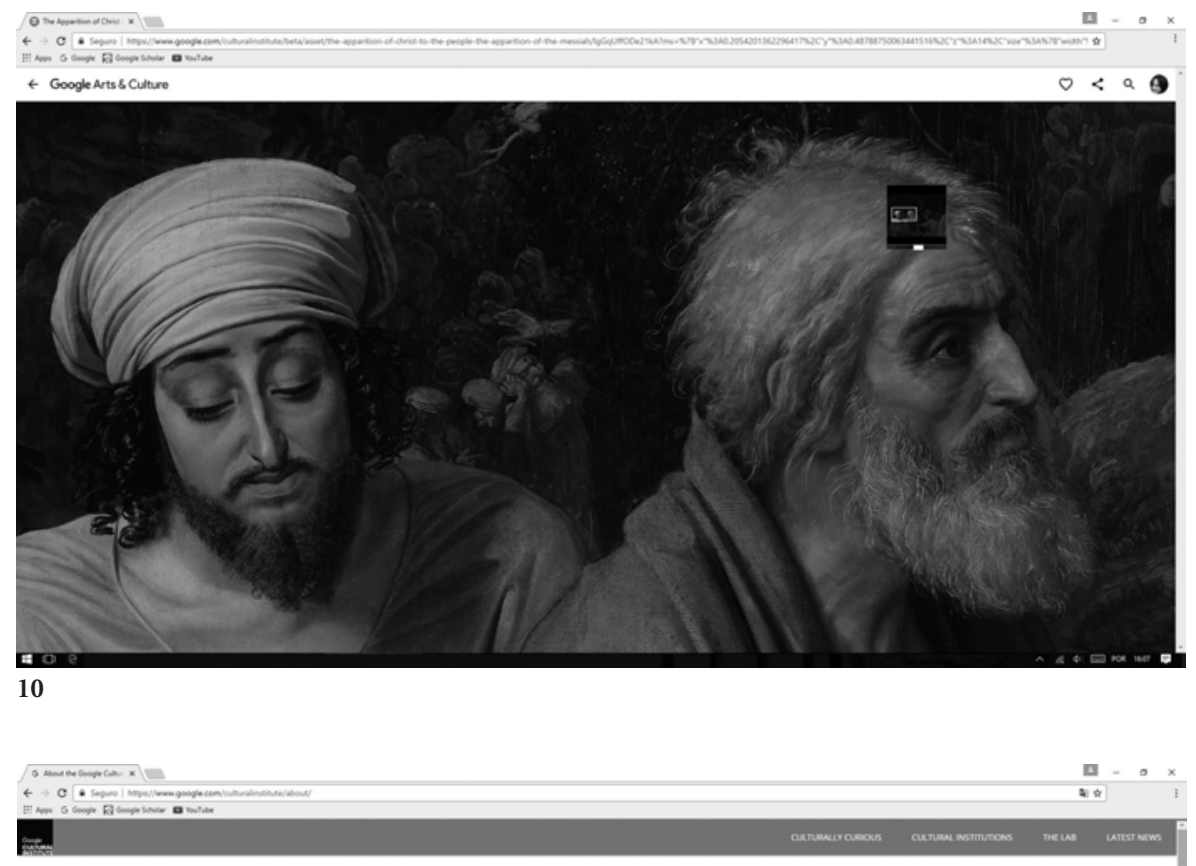

EXPLORE COULECTIONS FROM AROUND THE

WORLD WITH GOOGLE ARTS \& CULTURE,

CREATED BY GOOGLE CULTURAL INSTITUTE.

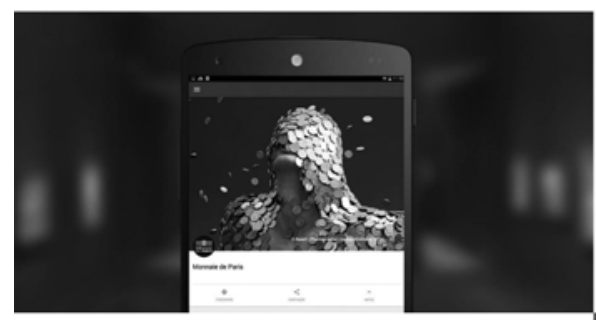

FOR THE CULTURALLY CURIOUS

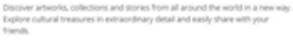

11

Figura 8a y 8b. Direita - GAP em Google+. Esquerda - GAP em Twitter.

Figura 9. The Apparition of Christ to the People, de Alexander Andreyevich Ivano.

Figura 10. Detalhe aproximado com as figuras escondidas atrás da árvore.

Figura 11. Home page do Google Cultural institute. 


\section{Novos Designs de Apreciação, Novas Oportunidades de Apreciação}

Diante de um mundo globalizado e conectado, as dinâmicas de comunicação e de circulação da informação devem ser repensadas a partir do paradigma tecnológico, em constante crescimento. E é, nesta contextualização, em relação à receptividade das expressões artísticas, que temos que pensar em como os objetos de arte são apreciados. Propomos o conceito operativo de design de apreciação, justamente, pelas variáveis que encontramos e lidamos ao receber e interagir com arte. O corpo do receptor, os suportes, os espaços, o tempo, entre outros fatores, tecem formatos de apreciação por meio dos movimentos causados pela cultura. Ou seja, pelas práticas de vida, como pudemos perceber ao longo do artigo.

A escolha da palavra design é pelo fato de ela trazer, em seu significado, as ideias de desenho, desígnio, de projeto, de beleza associada à utilidade e serventia. A arte não é mais somente sentida ou vista por mera apreciação, no sentido de admirar o objeto. A vida em rede, sustentada por uma conexão tecnológica, pede interação. $O$ apreciador não é mais só receptor passivo, mas sim um visitante, usuário e, até mesmo, um consumidor que atua, ativamente, com a arte. Ele se faz sujeito desta comunicação. Pode-se dizer que é ator da apreciação, em arte, por desempenhar papéis diferentes, dependendo da relação que estabelece com a expressão artística (Greimas y Courtés, 2008, p. 44) ${ }^{7}$.

Se de um lado, temos o corpo interativo do apreciador de arte, de outro, temos também que considerar os espaços em que a comunicação acontece. Os lugares em que as cenas de recepção se processam são diversos: da visitação in loco à virtual. Esta última mediada em espaços físicos peculiares, a depender de onde o apreciador se encontra. Portanto há de se pensar que o sentido da palavra lugar se potencializou. Ele define o tipo de comunicação, isto porque, para se configurar, depende das relações e associações que estabelece com as variáveis de suporte, mediação e ambientação física, como podemos notar na afirmação dos estudos de Irene Machado (2015):

Noções como a de lugar passam a demandar um refinamento de acepção, sobretudo porque o ponto de vista da ressonância, as topografias passam a disputar espaço com topologias de variáveis relacionais e associativas. No limite, diríamos que o uso qualificado do espaço se torna modelização de códigos sempre renovados pelos meios de comunicação em expansão (p. 72).

A pesquisadora nos chama a atenção para o conceito operacional de modelização, advindo dos estudos de semiótica da cultura, do eixo Tártu-Moscou. A modelização foi um termo forjado da cibernética e informática, que significa processamento. Ou seja, para a nossa discussão, os espaços, em que os apreciadores se encontram, processam códigos dos ambientes que interferem e configuram o ato das apreciações. A operacionalidade da conceituação é esclarecida a seguir:

A modelização envolve um encadeamento de linguagens, sistemas, signos e códigos variados, pelo qual passa um determinado objeto. A finalização de tal mecanismo resulta em uma produção, em que o objeto é traduzido para 
um novo contexto que não o seu original. Nesta ação, ele pode ser recriado e reinventado por processos de recodificação, processando estruturalidades de outras linguagens. Passa a ter, portanto, uma estrutura de linguagem específica por meio de outras que participam de tal processo (Caminni, 2007, p. 40).

Explorando as mediações da plataforma digital, do GAP, percebe-se que a iniciativa assume papéis que o museu incorporou através do tempo: arquivo, orientação educacional, centro de cultura e pesquisa. A possibilidade de acesso a uma série de conteúdos visuais, as discussões entre curadores e experts da área artística ao vivo, por meio da mídia social Google+, vídeo aulas no canal do YouTube trazem uma sensação arrebatadora e excitante com a convergência de todas essas mídias culturais. Portanto, a interação, com estas modalidades, para o apreciar, modelizam códigos de tais ambientes, na relação com os lugares em que se encontram os usuários, gerando novos designs de apreciação.

Sendo assim, é por meio de uma cultura de convergência (Jenkins, 2008) que se tem a possibilidade de adentrar ao conhecimento em arte. O termo é usado para designar o fluxo de conteúdos em múltiplos mercados e plataformas de mídia e o comportamento cooperativo entre eles, que transformam a cultura e sociedade atuais. Surge a partir daí um apreciador com status de consumidor participativo, que migra entre mídias à medida que for incentivado a procurar novas informações e fazer novas conexões.

Faz-se necessário tratar a problemática por meio de abordagens teóricas que expliquem o quesito da contextualização. É nela que compreendemos ações, processos e produções que justificam a atual recepção em arte. Garcia Canclini (2010, p. 41) explora uma conclusão interdisciplinar, ao afirmar que a "cultura abarca o conjunto dos processos sociais de significação ou, de um modo mais complexo, a cultura abarca o conjunto de processos sociais de produção, circulação e consumo da significação na vida social". Estas três ações configuram os modos de apreciação, em um pano de fundo inter e/ou multicultural. E, até mesmo, transmidiático, como discutimos, inicialmente. Ora as relações processuais se dão entre elas, ora se multiplicam em variáveis de escolhas e possibilidades. Ou ainda se processam pelas operações de uma mídia a outra. O fato é que as configurações para o apreciar irão depender de como as informações circulam na cultura.

Por este viés, pode-se dizer que a iniciativa do Google Art Project aproxima-se de uma proposta multicultural, quando se propõe a disponibilizar conteúdos de museus pelo globo, colocando, lado a lado, a produção cultural de diversos países. Isso ocorre por meio de museus parceiros, que fizeram sua própria curadoria com relação aos conteúdos disponibilizados. A Pinacoteca do Estado de São Paulo, por exemplo, disponibiliza o recurso de visitação virtual em primeira pessoa. Já o Museu de Arte de São Paulo expõe parte de seu acervo, bem como algumas exposições pontuais.

Contudo, o GAP poderia ser considerado intercultural? Como definição de sua identidade, não. Ele está mais para multicultural. Mas as suas operações não deixam de ser interculturais. De acordo com Canclini (2010, p. 17), o adjetivo intercultural remete à "confrontação e ao entrelaçamento, àquilo que sucede quando os grupos entram em relações ou trocas” entre as suas culturas. Já para Milton J. Bennett $(2011)^{8}$ : 
A comunicação intercultural é uma evolução da teoria da comunicação para um contexto mais global; defende que as pessoas precisam primeiro entender a si, aprender a dar significado a suas próprias formas de comunicação, para só então poder criar significados que façam sentido para todos os outros (s/p).

A discussão é polêmica, mas o que nos importa são as ações e possibilidades que estes prefixos, enquanto elementos comunicacionais, permite-nos a fazer para interagimos com arte. A plataforma do GAP oferece ferramentas que proporcionam o desenvolvimento de "habilidades interculturais" - expressão utilizada por Bennett (Ibid.) ao explicar interculturalidade. Então, deste ponto de vista, o Google Art Project opera-se por meio de ações interculturais entre seus usuários. A oferta de opções para o conhecimento e apreciação em arte é multi, mas as ações dos e entre usuários intenciona-se inter. Portanto o GAP propõe uma linguagem que permite ações inter e multiculturais entre os seus usuários, sejam estes apreciadores ou artistas, como podemos ler a seguir.

A plataforma prevê a pesquisa de obras de arte por meio de diversas ferramentas de busca, separando-as em seções: movimentos artísticos, artistas, coleções de museus e fatos históricos. Também cria possibilidades de recortes dos acervos pela aba "favoritos", na qual o usuário tem a possibilidade de curar a sua própria exposição.

O chamado The Lab, do Cultural Institute, foi criado como "um lugar onde as comunidades de tecnologia e criatividade juntam-se para partilhar ideias e descobrir novos modos de experimentar arte e cultura" . Isto é, a ferramenta dá a possibilidade de vivenciar, de sentir novas e outras sensações - são novos sentires, outras estesias. O que não seria possível em uma visitação física. Já o 89 Plus é um exemplo de residências artísticas realizadas pelo globo. Convida artistas, nascidos depois de 1989, para workshops com os curadores Hans Ulrich Obrist e Simon Castets por meio de apresentações dos trabalhos dos participantes. Um deles ocorreu no Rio de Janeiro, no Museu de Arte Moderna, em 2014.

Outro exemplo, para design de apreciação, esteve na aba projetos, do ano de 2016. Estava em destaque como Rio: além do mapa $a^{10}$. O projeto propunha-se a explorar as favelas do Rio de Janeiro em $360^{\circ}$, em primeira pessoa. Um apresentador convidava o público a conhecer a favela, a partir das perspectivas de histórias escolhidas de determinados moradores. Eram histórias sobre violência, cotidiano e superação de personagens. Esse tipo de narrativa costuma ser muito popular no exterior. A partir do Google Cultural Institute, a empresa se coloca como mediadora da cultura mundial. As perspectivas abordadas nem sempre são locais, mas sim de uma visão internacional que se tem de um determinado país.

A iniciativa do Cultural Institute e do Art Project parece uma consequência utópica da globalização. Entretanto, deve-se levar em consideração que é uma iniciativa de uma empresa privada, que criou mais um veículo centralizador de informação, controlado por suas próprias normas e interesses. E isto pode ser alterado ou tirado do ar a qualquer momento. A nossa discussão não é de cunho mercantilista, mas sim cultural, no que tange as práticas de vida. O foco está em perceber como os movimentos da cultura interferem em nosso comportamento e, no caso, no objeto de nossa pesquisa: apreciação em arte. Iuri Lotman (1996, p. 24), em sua proposta sobre semiosfera, aborda a cultura como um "organismo vivo". O pesquisador criou este termo a partir das ideias de Vladímir Ivanovich Vernádski 
sobre biosfera, em uma exploração do conceito por analogia com a cultura. Para ele, a biosfera diz respeito ao nível biológico. Já a semiosfera trata dos níveis aonde habitam os signos entre os diversos sistemas da cultura - o mundo dos signos. Ou seja, todos os processos e produções originados e causados pelos movimentos da cultura. E é nesta contextualização que são produzidos novos sabores e novas formas de apreciação, resultados de práticas tecnológicas que fazem parte do nosso dia a dia.

As comunicações virtuais, geradas pela cultura digital, possibilitam produções de linguagens específicas e, até mesmo, inusitadas, que mudam os nossos modos de apreciação. No GAP, a publicidade atravessa fronteiras de uso comum e atinge outras topografias culturais por meio dos movimentos de seus usuários. Gira ainda em torno da tecnologia aplicada para um fim artístico, ao incentivar o culto ao novo, a necessidade do consumo de mudanças que, dentro da tecnologia, vem crescendo a partir da revolução industrial e acelerando a níveis incríveis a partir dos anos 2000.

O consumidor está, portanto, cercado pelo Google por todos os lados. Um grande volume de dados sobre ele está sendo gerado e armazenado pela empresa. Mas aí, cabem atitude e posicionamento que os indivíduos precisam desenvolver e colocar em prática: a escolha e seleção do que querem. Estamos tendo a oportunidade de viver a democratização da cultura. Posicionar-se é, cada vez mais, necessário, nos dias de hoje, diante de tudo o que vivemos e do que nos é oferecido.

O Google Art Project democratiza a cultura. O que queremos dizer é que ele possibilita conhecimentos e oportunidades estéticas e estésicas para um grande número de pessoas, socialmente distintas por meio de novos designs de apreciação. Torna o conhecimento cultural acessível, traz a possibilidade de o usuário interagir mais com a arte do que seria corrente nos museus, viabiliza criações de exposições com uma grande quantidade de conteúdos artísticos disponíveis, sem ter que lidar com aspectos burocráticos e legais das instituições.

Mesmo assim, logo no seu lançamento, o projeto gerou questões e críticas. Alastair Sooke, crítico de arte do jornal inglês The Telegraph, levantou uma série de apontamentos que considerava problemáticos ${ }^{11}$. Chamou a atenção para o fato de que nem todos grandes museus faziam parte do projeto; não considerou a experiência da tecnologia do Google Street View, aplicada aos museus, como satisfatória; questionou a seleção das obras expostas pelos museus, ressaltando que outras pessoas estão escolhendo pelo usuário o que deve ser; também questionou as obras selecionadas por cada museu para serem digitalizadas com a tecnologia de giga-pixel entre outros apontamentos.

Outra crítica levantada foi se a existência de museus on-line anularia a vontade ou a necessidade do público de visitar a instituição em si. Ruth R. Perlin (2000, p. 82) afirma: "Ao abraçar a mídia dentro do museu e além dele, estamos diluindo a experiência de encontro com a arte? A resposta, eu acho, é não. A mídia, propriamente usada, pode melhorar exibições, alcançar e engajar audiências e iluminar obras de arte".. Encontramos também um posicionamento relevante no documentário sobre o GAP, apresentado pelo $T E D^{12}$, em que Amit Sood diz ao ser questionado: "Você fez isso para replicar a experiência de ir a um museu? A resposta é não, é para adicionar à experiência".

O espaço do museu na WEB está se construindo, se definindo desde os primeiros experimentos nos anos noventa (Sbrilli, 2012). Mas, com certeza, já caiu no gosto do público e 
conquistou território. Stephen Borysewicz, em seu texto Networked Media: the experience is closer than you think, de 1998, levanta uma questão interessante sobre o museu virtual a partir desta data: "O que faremos a seguir?" Dentre as respostas sugeridas pelo autor, estão opiniões que se articulam, perfeitamente, ao conceito do GAP: 1.Criar um contínuo e aberto diálogo entre a audiência sobre os conteúdos apresentados; 2. Deixar nossos visitantes criarem seus próprios museus; 3 . Divulgar na web diversos pontos de vista diferentes, combinando acervos; 4. Manipulação segura dos objetos - objetos observados pela web não ameaçam o acervo e podem ser vistos em detalhes.

O museu virtual, acessível e democrático e, portanto, expandido e estendido, não é uma ideia nova, mas sim uma ideia realizável. Ele permite customização e criação de galerias de imagens a partir da curadoria de cada usuário. É a liberdade de escolha, de construir conhecimentos e de usufruir de repertório, quando se tem.

O GAP está longe da perfeição, mas caracterizá-lo como moda, diluição de conteúdos ou experiência pela metade é ignorar os passos da humanidade durante sua existência, neste planeta, e descartar uma importante ferramenta de inclusão, socialização e difusão cultural. Ele é um dos meios para transcender as fronteiras da arte. O ser humano ascende por meio do autoconhecimento, da sensibilidade e percepção. É isso que o faz apreciar com estesia. Os novos designs de apreciação, em arte, abrem possibilidades de avançar, no universo da beleza, do sensível e do conhecimento, dando oportunidades a todos.

\section{Notas}

1. Autorretrato feito normalmente com câmeras de celular para ser compartilhado nas mídias sociais.

2. No início de 2015 foi aberto o museu interativo Art on Island, nas Filipinas, onde o visitante fotografa interagindo com famosas obras de arte.

3. Texto original de 1998.

4. ZANINI, Walter. Os museus e os novos meios de comunicação. O Estado de São Paulo, São Paulo, 7 de marzo de 1976, p. 23.

5. Apesar de o projeto se chamar Google Art Project, em sua página de navegação, no canto superior esquerdo, consta o nome Google Arts \& Culture. De acordo com consulta no ano de 2019.

6. Em entrevista para o jornal inglês The Guardian, em 2 de dezembro de 2013.

7. Conferir GREIMAS, Algirdas Julien \& COURTÉS, Joseph. Dicionário de Semiótica, 2008. Os autores trabalham a ideia de ator para a abordagem da construção e desenvolvimento dos discursos.

8. Interculturalidade. Você sabe o que é? Em: http://revistaepoca.globo.com/Revista/ Epoca/0,,EMI250960-15228,00-INTERCULTURALIDADE+VOCE+SABE+O+QUE+E. html

9. Informações disponíveis em https://www.google.com/culturalinstitute/thelab/\#explo rations 
10. O projeto esteve em função das Olimpíadas de 2016, na cidade.

11. The problem with Google's Art Project. Em: http://www.telegraph.co.uk/culture/art/ art-news/8296251/The-problem-with-Googles-Art-Project.html

12. TED (Tecnologia, Entretenimento e Design) é um conjunto de conferências criadas sob o slogan "Ideas Worth Spreading”. Disponíveis na internet e dirigidas pela Fundação Árvore Jovem, uma instituição privada, sem fins lucrativos.

\section{Referências}

Bennett, M. (2019). Interculturalidade. Você sabe o que é? Disponível em: http://revistaepoca. globo.com/Revista/Epoca/0,,EMI250960-15228,00-INTERCULTURALIDADE+VOCE+ $\mathrm{SABE}+\mathrm{O}+\mathrm{QUE}+\mathrm{E} \cdot \mathrm{html}$.

Borysewicz, S. (2000). "Networked Media: the Experience is Closer than you Think" in: The Virtual and the Real: Media in the Museum. (A. Mintz \& S.Thomas, Orgs.). (2a ed.). Washington DC: American Association of Museums.

Caminni Pereira Da Silva, R. (2007). Atuante das Mídias: o Ator como Linguagem na Comunicação Mediada. Tese de doutorado, Pontifícia Universidade Católica, São Paulo, SP, Brasil.

Fowle, K. (2007). "Who Cares? Understanding the Role of the Curator Today" in Cautionary Tales: Critical Curating. (H. Kouris \& S. Rand, Orgs.). (1a ed.). Nova Iorque: Apexart.

Garcia Canclini, N. (2010). Diferentes, Desiguais e Desconectados: mapas da interculturalidade. (L. S. Henriques, Trad.). Rio de Janeiro: URFJ.

Greimas, A. J. \& Courtés, J. (2008). Dicionário de Semiótica. (A. D. Lima \& al., Trad.). São Paulo: Contexto.

Jenkins, H. (2009). Cultura de Convergência. (S. Alexandria, Trad.). São Paulo: Aleph.

Lotman, Y. (1996). La Semiosfera I: Semiótica de la Cultura y del Texto. (D. Navarro, Sel. \& Trad.). Madrid: Frónesis Cátedra - Universidade de Valência.

Machado, I. (2015). "Variáveis Semióticas do Espaço na Cultura de Meios" in Galáxia. São Paulo: Online, n. 29, junho, p. 70-82. Disponível em: http://revistas.pucsp.br/index.php/ galaxia/index.

Perlin, R. (2000). "Media, Art Museums and Distant Audiences" in The Virtual and the Real: Media in the Museum. (A. Mintz \& S. Thomas, Orgs.). (2a ed.). Washington DC: American Association of Museums.

Sbrilli, A. (2012). "Computerization, Digitalization and the Internet" in Art, History and Visual Studies in Europe: Transitional Discourses and National Frameworks. (M. Rampley \& al., Orgs.). Brill's studies on art, art history, and intellectual history, v. 4, The Netherlands, Brill.

Sood, A. (2019). "Arts Head: Amit Sood, director, Google Cultural Institute" in The Guardian. Entrevista concedida a Matthew Caines. Inglaterra, 3 de dezembro de 2013. Disponível em: http://www.theguardian.com/culture-professionals-network/culture-professionalsblog/2013/dec/03/amit-sood-google-cultural-institute-art-project. 
. (2019). Building a Museum of Museums on the Web. Produção de TED, filmado em março de 2011. 535 min. Disponível em: https://www.ted.com/talks/amit_sood_ building_a_museum_of_museums_on_the_web?language=en\#t-307291.

Sooeke, A. (2019). The Problem with Google's Art Project. Disponível em: http://www.telegra ph.co.uk/culture/art/art-news/8296251/The-problem-with-Googles-Art-Project.html.

Thomas, S. (2000). "Mediated Realities: A Media Perspective" in The Virtual and the Real: Media in the Museum. (A. Mintz \& S. Thomas, Orgs.). (2a ed.). Washington DC: American Association of Museums.

Tollon, L. y Walker, K. (2008). Digital Technologies and the Museum Experience: Handheld Guides and Other Media. (1a ed.). Altamira Press. Plymouth: United Kindom.

Willimans, D. (2010). "A Brief History of Museum Computerization" in Museums in Digital Age. (R. Parry, Org.). London: Routledge.

Zanini, W. (1976). Os Museus e os Novos Meios de Comunicação. São Paulo: diário O Estado de São Paulo, 7 de março.

. (2003). A Arte da Comunicação Telemática: a Interatividade no Ciberespaço. Sao Paulo: Revista Ars, v.1, n.1, p. 11-34.

\section{Figuras}

Figura 1: Museu Interativo Art on Island. Filipinas. Disponível em: http://www.criatives. com.br/2015/03/museu-interativo-3d-nas-filipinas-faz-com-que-voce-entre-dentrodas-pinturas/. Acesso em 14/03/2017.

Figura 2: Disponível em: TOLLON, Loïc \& WALKER, Kevin (2008). Digital Technologies and the Museum Experience: Handheld Guides and Other Media. (1a ed.). Altamira Press. Plymouth: United Kindom.

Imagem 1 - Telesonic Lorgnette, um "rádio guia" usado no Museu de Ciências, Londres, 1961. (p. XVI).

Imagem 2 - Áudio guia Sound-Trek em uso no museu americano de história natural, Nova Iorque, 1961. (p. XV).

Imagem 3 - Headfone duplo do áudio guia em uso na Galeria Nacional de Arte, Washington D. C., 1965. (p.XVIII).

Figura 3: Disponível em: https://en.wikipedia.org/wiki/Punched_card\#/media/File:Bluepunch-card-front-horiz.png. Acesso em 19/01/2019.

Figura 4: Home page do Google Art Project Disponible en: https://www.google.com/culturalinstitute/about/artproject/. Acesso em 21/01/2019.

Figura 5: Página com a lista de coleções dos museus e galerias parceiros do GAP. Disponível em: https://www.google.com/culturalinstitute/beta/partner?hl=pt- BR. Acesso em 21/01/2019.

Figura 6: Musée d'Orsay - Paris Disponível em: https://www.google.com/culturalinstitute/ beta/search/?q=d\%27orsay\&oq=dorsay\&hl=pt-BR. Acesso em 21/01/2019.

Figura 7: Musée d'Orsay, Paris, museum view. Disponível em: https://www.google. com/culturalinstitute/beta/streetview/mus\%C3\%A9e-d\%E2\%80\%99orsay-paris/ 
KQEnDge3UJkVmw?hl=pt-BR\&sv_h=272\&sv_p=0\&sv_pid=FjndSjvl55w8 1 vbNYu5DfA\&sv_lid=6004477680878644429\&sv_lng $=2.327089926444387 \&$ sv lat $=48.85968476784497 \&$ sv_z=1.0000000000000002. Acesso em 20/01/2019.

Figura 8: GAP en Google + y en Twitter. Disponível em: https://plus.google.com/s/google\%20 art\%20project/top. Acessado em: https://twitter.com/googlearts. Acesso em14/03/2017. Figura 9: The Apparition of Christ to the People, de Alexander Andreyevich Ivano. Galeria Tretyakov-Moscou. Disponível em:https://www.google.com/culturalinstitute/beta/asset/ the-apparition-of-christ-to-the-people-the-apparition-of-the-messiah/lgGqUffODe 21kA. Acesso em 21/01/2019.

Figura 10: The Apparition of Christ to the People, de Alexander Andreyevich Ivano. Galeria Tretyakov - Moscou. Disponível em: Detalhe aproximado com as figuras escondidas atrás da árvore. https://www.google.com/culturalinstitute/beta/asset/the-apparition-ofchrist-to-the-people-the-apparition-of-the-messiah/lgGqUffODe21kA?ms $=\% 7 \mathrm{~B} \% 22 \mathrm{x}$ \%22\%3A0.2054201362296417\%2C\%22y\%22\%3A0.48788750063441516\%2C\%22z\%2 2\%3A14\%2C\%22size\%22\%3A\%7B\%22width\%22\%3A0.11438412110716151\%2C\%2 2height\%22\%3A0.08273722313194863\%7D\%7D. Acesso em 21/01/2019.

Figura 11: Home page do Google Cultural institute. Disponível em: https://www.google. com/culturalinstitute/about/. Acesso em19/01/2019.

Resumen: Este artículo se propone reflexionar sobre la apreciación del arte, ante la comunicación tecnológica. La cultura, como un organismo vivo, en sus movimientos, genera y produce lenguajes. Los lugares en que las escenas de recepción se procesan son diversos: desde la visita in situ a la virtual. El sentido de la palabra lugar se vio potenciado con el universo online, procesando nuevas formas de recibir y sentir el arte. El formato museo es el eje de los cuestionamientos y el proyecto Google Art Project - GAP es el corpus referencial que guía el pensar sobre la problemática. Este abre posibilidades a varios sentires y elecciones del usuario, en la relación con los objetos del arte, en una mediación virtual. Nombramos design de apreciación a los nuevos formatos estéticos, para recibir e interactuar con el arte, por su funcionalidad para con el apreciador. La reflexión se fundamenta y articula por medio de las ideas sobre cultura, arte y museos, de Yuri Lotman, Milton J. Bennett, Néstor Canclini, Walter Zanini, Selma Thomas, respectivamente, entre otros.

Palabras clave: Tecnología - Arte - Museo - Google Art Project - Virtual - Designs de Apreciación - Cultura - Mediación - Interactividad - Usuario.

Abstract: This article proposes to reflect on the appreciation of art, in the present day, in front of technological communication. Culture, as a living organism, in its movements, generates and produces languages. The places where the reception scenes take place are diverse: from visitation in loco to virtual. The meaning of the word place became potent with the online universe, processing new ways of receiving and feeling art. The museum format is the axis for questioning and the Google Art Project - GAP is the referential corpus 
that directs the thinking of the problem. It opens up possibilities for various user feelings and choices, in relation to the objects of art, in a virtual mediation. We named designs of appreciation, the new aesthetic formats, to receive and interact with art, for its functionality towards the connoisseur. Yuri Lotman, Milton J. Bennett, Néstor Canclini, Walter Zanini, Selma Thomas, and others, among others, are based on the ideas of culture, art and museums.

Keywords: Technology - Art - Museum - Google Art Project - Virtual - Designs of Appreciation - Culture, Mediation - Interactivity - User.

[Las traducciones de los abstracts fueron supervisadas por el autor de cada artículo] 